\title{
Femininity and their rights violation - A case study
}

Karishma Karim Halani \& Shaileen Karim

k_halani@hotmail.com

\section{Abstract}

This paper highlights the concept of women rights violation and male dominancy over women. Further, it will discuss the causes that are responsible for it such as cultural values, traditions, family restrictions, rearing styles and lack of women empowerment. Along with this, all the causes are responsible for several impacts those are helplessness, low self-esteem and confidence etc. Moreover, practical recommendations are shared to reduce this problem. Research journals from 2012-2013 were chosen and considered to discover reliable and divergent analysis. Male dominancy, family values, stigma and women values are the topics that were preferred to read. These topics will come across throughout this literature review. It was clearly understood that women have a diverse prospects and mores according to her culture that influences their way to health care. It is vital to support educational systems and healthcare providers to spread awareness related to women rights. This attempt will assist in rising public knowledge. It will also promote effective care to women and ultimately the whole family. Concluding that violation of women rights and male dominancy are the vital and most important issue to be addresses. Certain recommendations that can be done to reduce this problem are as follows a) Student as human rights advocator can aware women about acceptable behaviors of family and should teach to differentiate between right and wrong behaviors b) Nurses should assure social protection for women c) Nurse as an education promoter should make sure that women should be on priority for health literacy.

\section{Key words}

Women empowerment, rights violation, lack of awareness, gender discrimination

\section{Introduction}

"Shock absorbers" - this is what women have been considered across years. Privileges of women have been challenged, criticized and rejected by men in the name of cultural and societal values. Men's power over bodies of women is a crucial issue that hinders almost every part of life especially healthcare sector. Women are depriving their rights of health due to this major problem. These socio-cultural values and customs influence women and their health-seeking attitudes.

\section{Case Study}

A situation was encountered at a renowned hospital. There was a 21 years old woman admitted in ward for elective lower segment caesarian section. It was her first post-op day when a nurse went to visit her. She was with her husband and mother in law at that time. When she was asked to have a walk in the corridor, her husband shouted, as he did not want males in the corridor to see her. Afterwards, woman was forced to wear veil by her husband even after, she was not able to carry its weight. After few time, situations made it evident that the woman was not allowed to make decisions related to her health too. Family planning teaching was also refuse by the family. Her expressions showed her exhaustion. Finally, she expressed an interest to know her rights.

\section{Literature Review}

According to Mare (2012), culture has imposed prejudice for women as compared to men. This biasness reduces self-confidence and self-worth of women and thus leads to delay in health seeking by women. Amoudi (2012) stated, "I believe that a woman has many rights but that one of the most important is her right to health care". This case study rooted several factors that lead to male dominancy and family restrictions. Main factor among them is family values and rearing styles. Same cause goes with the woman in the case study; as the woman was compelled to do whatever her husband say in order to be an ideal girl. Another cause was lack of women empowerment. According to Amoudi (2012), women are not raised in such a way that she could be able to decide for her own self. After marriage, in-laws and husband are the only ones who are allowed to decide for women's problems that influence her life. Furthermore, religion is also put forward in the favor of male dominance. It is important for the favorers of male dominance to understand that there is a huge distinction between respect and weakness. It's necessary to understand that religion always promotes respect for all but it would be a great mistake if society overlaps respect with the weakness of women. All these factors are causing troublesome impact on women, as they always feel helpless and do 
not have any other choice but to silently bear all the troubles without complaining about husbands' attitude, family's cruelty and egoism.

It is important to eliminate these gender inequalities in order to promote efficient approaches to health, diet, sanitation encouragement and disease prevention (World Health Organization, 2013). As an education promoter, one should make sure that women should be on priority for health literacy as they are the chief health care providers for their family, children and themselves. Secondly, as a human rights advocator, an individual can aware women about acceptable behaviors of family and should teach how to differentiate between right and wrong behaviors. Apart from this, being a government official, women's participation should be increased in policy making so the issues with women can't be ignored. Likewise, as a non-governmental organization worker, the development of self-help groups can help for the socioeconomic empowerment of women. Furthermore, healthcare providers should conduct workshops for couples to aware advantages of family planning (Azmat et al., 2012). Likewise, a healthcare provider should teach patient to verbalize her feeling assertively or a healthcare provider can be an advocate for a patient as well (Schwartz, 2002).

\section{Conclusion}

On conclusion, it was clearly understood that women have a diverse prospects and mores according to her culture that influences their way to health care. It is vital to support educational systems and healthcare providers to spread awareness related to women rights. This attempt will assist in rising public knowledge. This may also improve life expectancy and promotes effective care to women.

\section{References}

- Ali, T. S., Karamali, N., \& Malik, O. (2014). Women's Perception and Attitude towards Male Dominancy and Controlling Behaviors. Arts and Social Sciences journal. Retrieved from http://dx.doi.org/10.4172/2151-6200.S1-004

- Amoudi, S. A. (2012, August 2). Women's health rights in Saudi Arabia. Retrieved from http://english.alarabiya.net/views/2012/08/02/22 9955.html

- Azmat, S. K., Mustafa, G., Hameed, W., Ali, M., Ahmed, A., \& Bilgrami, M. (2012). Barriers and perceptions regarding different contraceptives and family planning practices amongst men and women of reproductive age in rural Pakistan: a qualitative study.Pakistan Journal of Public Health, 2(1). Retrieved from http://mariestopespk.org/wpcontent/uploads/Barriers-and-Perceptions.pdf

- Doepke, M., Tertilt, M., \& Voena, A. (2012). The Economics and Politics of Women's Rights.Annual Review of Economics, 4. doi:10.1146/annureveconomics-061109-080201

- Mare, A. L. (2012). 'Show the world to women and they can do it': Southern fair trade enterprises as agents of empowerment. Gender \& Development, 20(1). doi:10.1080/13552074.2012.663608

- Schwartz, L. (2002). Is there an advocate in the house? The role of health care professionals in patient advocacy. Journal of Medical ethics, 28(1), 37-40. doi:10.1136/jme.28.1.37

- World Health Organization. (2012). Gender. Retrieved from http://www.who.int/trade/glossary/story032/en/

- Youngs, G. (2003). Private Pain/Public Peace: Women's Rights as Human Rights and Amnesty International's Report on Violence against Women. Chicago Journals - Signs, 28(4). doi:10.1086/368325 